\title{
Technical Specification and Bid Evaluation: Major Bottlenecks in Equipment Procurement in a Public Sector Tertiary Care Hospital
}

\author{
${ }^{1}$ Shweta Prabhakar, ${ }^{2}$ AK Singhal, ${ }^{3}$ Shikha Vardhan
}

\begin{abstract}
Introduction: The innovation of modern medical equipment with wide diversity has contributed immensely in improving the quality of healthcare and state of health profile of nations. For effective and efficient control on procurement of medical equipment, it is required to control the lead time (internal) as limited scope exists in case of external lead time.
\end{abstract}

Objectives: The study was conducted to analyze the lead time with an aim to identify the issues/bottlenecks and to suggest the appropriate remedial measures in a public sector Tertiary care Hospital.

Materials and methods: A retrospective exploratory study was undertaken. A total of 50 such capital equipment was procured in this hospital during March 2007 to 2010 (3 years) were included in this study.

Results: It was observed that the procurement procedure in public sector tertiary care hospital is as per the standard guidelines prescribed by Government of India in General Financial Rules and guidelines issued by MOHFW and DGHS in this regard. The lead time analysis showed that there is a variation in the total lead time, internal lead time (ILT), external lead time (ELT) and their components. It was observed that ILT2 and ILT4 component constituted around $70 \%$ of the total ILT for almost all the equipments under study. In case of ELT, $75 \%$ time was consumed by ELT1, i.e. the delivery time and receipt of equipment.

Conclusion: Since activities in both ILT2 and ILT4, i.e. laying down the technical specification and bid evaluation are the responsibility of the individual department, the overall delay can also be attributed to the individual departments. This is in contrast to the general impression that there is delay on the

${ }^{1}$ Medical Superintendent, ${ }^{2}$ Additional Medical Superintendent and Associate Professor, ${ }^{3}$ Assistant Professor

${ }^{1}$ Swasthya Hospital and Medical Research Center, Ahmednagar, Maharashtra, India

${ }^{2}$ Department of Hospital Administration, Dr Ram Manohar Lohia Hospital and PGIMER, New Delhi India

${ }^{3}$ Department of Community Medicine, Dr Ram Manohar Lohia Hospital and PGIMER, New Delhi, India

Corresponding Author: Shweta Prabhakar, Medical Superintendent, Swasthya Hospital and Medical Research Center, Ahmednagar, Maharashtra-414001, India, Phone: 09049497553, e-mail: shweta19dec@gmail.com part of purchase department. On an analysis of lead time as per VED category, it has been concluded that no concept of VED analysis is applied in the procurement of equipment. On further analysis of lead time analysis, it was concluded that the shortest time was taken by proprietary purchase followed by open tender and maximum time in open tender where approval from higher authority was required.

Keywords: Capital equipment, Procurement, Internal lead time, External lead time, VED, Public sector tertiary care hospital.

How to cite this article: Prabhakar S, Singhal AK, Vardhan S. Technical Specification and Bid Evaluation: Major Bottlenecks in Equipment Procurement in a Public Sector Tertiary Care Hospital. Int J Res Foundation Hosp Healthc Adm 2014;2(2): 103-110.

\section{Source of support: Nil}

Conflict of interest: None

\section{INTRODUCTION}

Health technologies and medical devices are crucial in the prevention, diagnosis and treatment of illness and diseases, as well as patients' rehabilitation. In recent years, the need of improved Healthcare Technology Management (HTM) practices have been recognized and addressed at numerous international forums. The factors identified are mainly related to inadequate planning, inappropriate procurement, poorly organized and managed healthcare technical services, and a shortage of skilled personnel. The health facilities in many countries, like India, are overburdened with many problems, one of which is non-availability and/or nonfunctioning of medical equipments. ${ }^{1}$

Since the declaration of Alma-Ata in 1978, World Health Organization (WHO) had highlighted the importance of appropriate technology and better standardization of health and medical technologies. World Health Organization launched a global action plan on management, maintenance and repair of medical equipments. The 113th session of the executive board in January 2004 concluded that countries need to develop national regulations, systems for quality assurance, procedures for procurement and risk assessment. These provided a useful foundation and reference for healthcare technology, policy formulation and implementation. ${ }^{2}$

The innovation of modern medical equipment with wide diversity has contributed immensely in improving the 
quality of healthcare and state of health profile of nations. ${ }^{3}$ Current estimates of medical equipment show that there are around 6,000 distinct device types and entities and 750,000 brands and models on the market, available from over 12,000 manufacturers worldwide. The spectrum of equipment ranges from simple one to the more sophisticated ones. Health facilities have to cope with this wide range of products. It has become difficult for developing countries to select and obtain the technologies appropriate to their needs. ${ }^{1}$ With increasing dependence on medical equipment, the importance of investments in medical equipment cannot be denied. The purchase process for medical equipment and services may vary from one organization to another but there are some key elements that are common throughout in all types of organizations. In public sector healthcare institutions, there is a common perception that the procurement process for equipment has an unusual long gestation period. This, at times, results in cost overrun and procuring outdated technology. This results in waste of already meager resources in the hospital, which in turn leads to a decrease in the quality of health care services. An effort should be made at all stages of procurement which should facilitate acquiring the latest equipment keeping in mind the rapidly changing scenario of hospital equipment and technologies. ${ }^{4}$

For effective and efficient control on procurement of medical equipment, it is required to control the lead time (internal) as limited scope exists in case of external lead time. The internal and external lead time has various components and hence the bottlenecks, which necessitates the need of the present study. The study aimed to explore and identify the challenges associated with the lead time of capital medical equipments. The study was undertaken for medical equipment costing more than 10 lakh so as to focus on the core issues involved in the procurement process of major equipment in a central government tertiary care hospital, Delhi. Hence, the study was undertaken with the following objectives:

1. To conduct the lead time analysis of capital medical equipment (costing $>10$ lakh) in public sector tertiary care hospital.

2. To identify the issues/bottlenecks in various stages of procurement process of medical equipment in public sector tertiary care hospital.

3. To suggest the appropriate remedial measures to overcome the identified bottlenecks.

\section{MATERIALS AND METHODS}

The hospital under study is one of the largest hospitals of Central Government in Delhi, with 1100 beds and having various superspecialty services, and large number of sophisticated equipment.

A retrospective exploratory study was undertaken at a public sector tertiary care hospital during March 2007 to 2010. A total of ' 50 ' medical equipment, costing more than 10 lakh, procured during the above said period of 3 years (March 2007- March 2010) were studied. As per the purchase guideline of DGHS, the procurement cycle of the hospital under study has various steps/stages (Fig. 1). The lead time of equipment under study has been divided into internal and external and they are further subdivided into various subcomponents (Table 1) based on the equipment procurement cycle of the hospital under study.

The data on lead time (internal and external) for each of the capital equipment under study was collected using the structured proforma with respect to the department (where it was used), criticality of the equipment (VED) and type of purchase process involved for it. Each equipment case history was explored retrospectively from the 'records' and by verbal 'interview' from the concerned heads of the department, officer-in-charge and purchase department.

The equipments records were scrutinized for primary data from (a) purchase files of equipments for internal lead time assessment, which consisted of demand performa, note-sheets of all relevant date, specification formulation, documents related to tender process, comparative charts of technical and financial bids, sanction performa, supply order, document related to internal payment; (b) equipment record file in stores for external lead time assessment which depicted information like receipt of equipment, installation report, satisfactory report and final bill payment. Besides records, the personal interview was also conducted with 'head of the departments', 'officer-in-charge' and 'staff' handling the equipment.

The collected data for each of the capital equipment was compiled on a master chart on Microsoft Excel and SPSS software with respect to the department, criticality of the equipment (VED) and type of purchase process involved for it. The data were analyzed for the 'average duration' for internal and external lead time for each variable under study and depicted graphically using bar diagram and pie charts beside tabular presentation.

\section{RESULTS}

The procurement cycle of equipment in this hospital follows general financial rules 5 and policies and procedures of purchase of goods, issued by Ministry of Finance Department and purchase guidelines issued by DGS and D, ${ }^{6}$ guidelines issued by Integrated Finance Division of Ministry of Health and Family Welfare and Empowered Procurement Wing of DGHS, etc. (Fig. 1). 


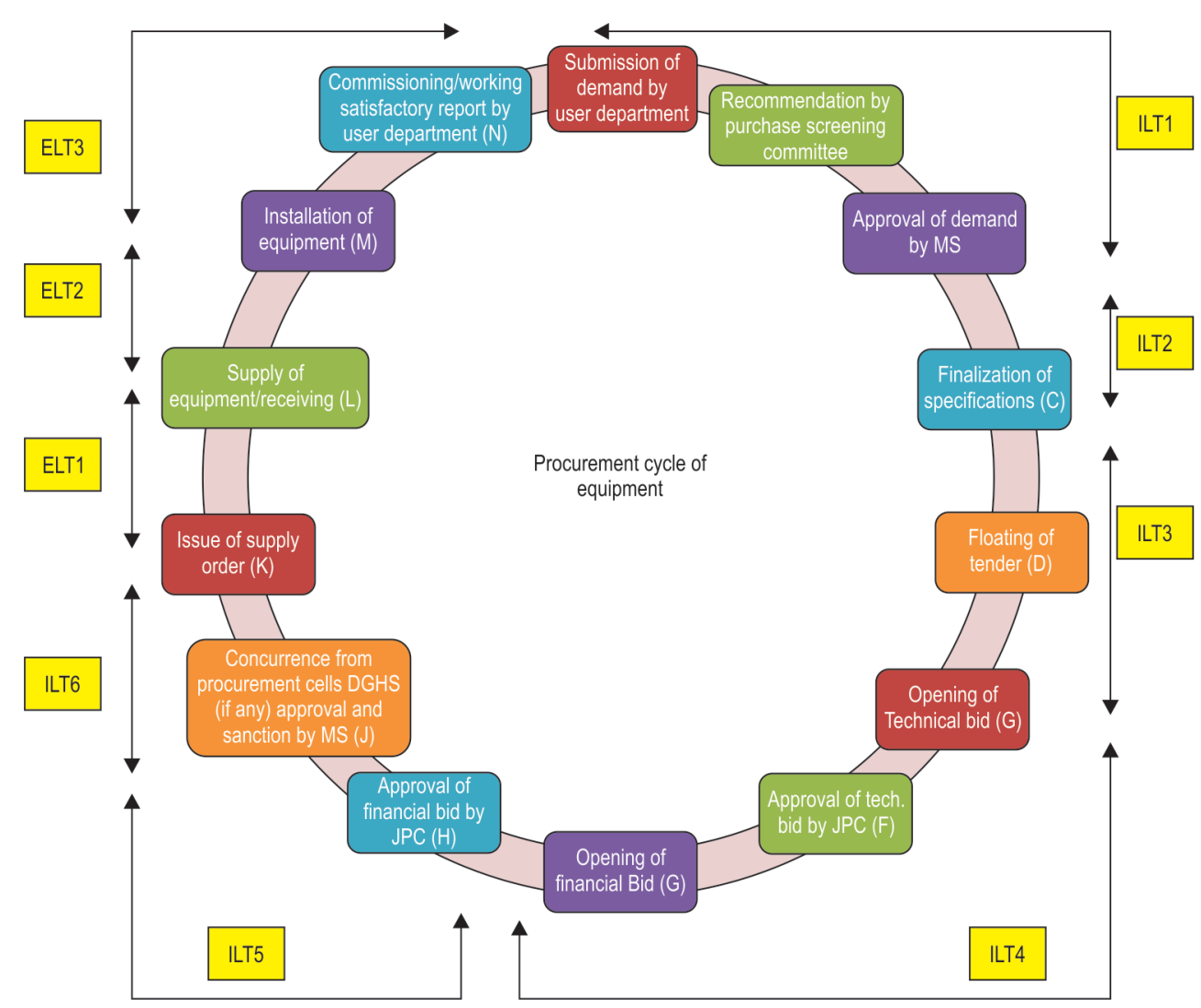

Fig. 1: Procurement procedure of equipments in a public sector tertiary care hospital (under study)

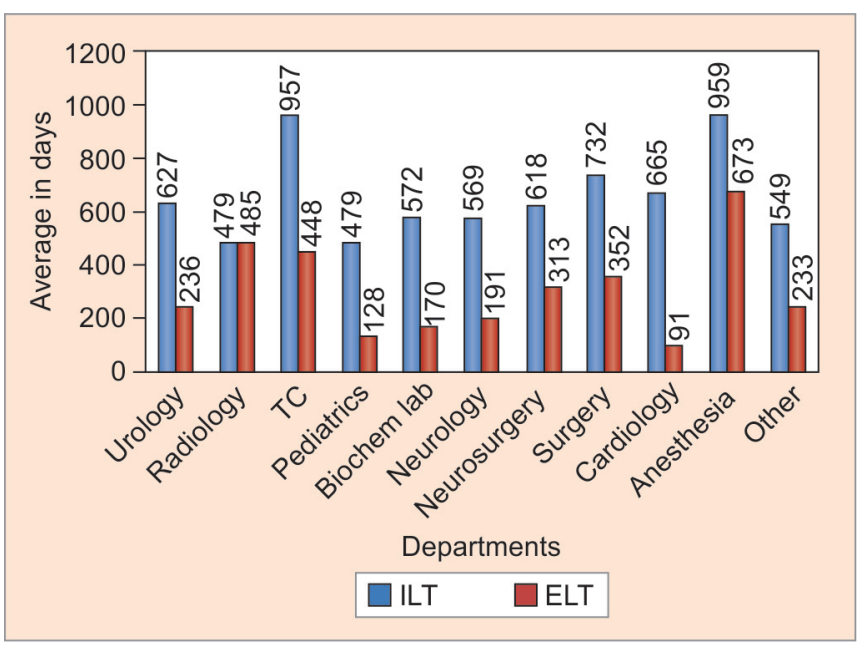

Graph 1: Department-wise analysis of lead time analysis

\section{Department-wise Analysis of Lead Time of Capital Equipment}

The data of present study indicate that capital equipment in various departments had different internal and external lead time (ILT and ELT). The highest 'average ILT' was seen in equipment belonging to Trauma centre/casualty and anesthesia department while the lowest 'average ILT' was observed in pediatrics and radiology department. Similarly, the highest 'average ELT' was seen in equipment belonging to anesthesia followed by radiology department, whereas lowest 'average ELT' was seen in cardiology and pediatrics department (Graph 1).

\section{Internal Lead Time-Department Wise}

The subcomponents wise analysis of ILT is depicted in Table 2. The highest value of maximum ILT subcomponent was observed as follows: ILT1: anesthesia, ILT2: surgery, ILT3: pediatrics, ILT4: trauma care centre/Casualty, ILT5: radiology and ILT6: anesthesia. On the contrary, lowest value of minimum ILT subcomponent was observed as follows: ILT1 and 2: radiology, ILT3: neurosurgery, ILT4: pediatrics, ILT5 and 6: cardiology.

Intra departmental observations: It was observed that major components of ILT in almost all the departments was ILT4 followed by ILT2, i.e. technical bid evaluation followed by framing the specifications. The other components of ILT did not consume abnormal time.

\section{External Lead Time-Department Wise}

The subcomponents wise analysis of ELT is depicted in Table 3. The highest value of maximum ELT subcomponent was observed as follows: ELT1 and 2: anesthesia, ELT3: radiology. On the contrary, lowest value of minimum ELT subcomponent was observed as follows: ELT1: 'laboratory and blood Bank', ELT2: pediatrics, and ELT3 anesthesia and cardiology.

It was further observed that ELT1 was the major time component vis-a-vis of total ELT in almost all the departments followed by ELT2 component. However, 
Table 1: Internal and external lead time categorization

Time period in days

\begin{tabular}{ll}
\hline & Time period in days \\
\hline Internal lead time & From demand forecasting to the demand approval \\
ILT2 & From demand approval to the specification formulation \\
ILT3 & From specification formulation to the floating of tender document \\
ILT4 & From opening of tender to the tender approval by JPC \\
ILT5 & From JPC approval to the approval by competent authority (MS/DGHS) \\
ILT6 & From approval/sanctioning of competent authority to the issue of supply order \\
External lead time & \\
ELT1 & From the issue of supply order to the receipt of equipment at store \\
ELT2 & From the receipt of equipment to the installation in the department \\
ELT3 & From the installation to the commissioning of equipment, working satisfactory report by user department \\
\hline
\end{tabular}

Table 2: Department-wise different components of ILT

\begin{tabular}{|c|c|c|c|c|c|c|c|c|c|c|c|c|c|c|c|c|c|c|}
\hline \multirow[t]{2}{*}{ Department } & \multicolumn{3}{|c|}{ ILT1 } & \multicolumn{3}{|c|}{ ILT2 } & \multicolumn{3}{|c|}{ ILT3 } & \multicolumn{3}{|c|}{ ILT4 } & \multicolumn{3}{|c|}{ ILT5 } & \multicolumn{3}{|c|}{ ILT6 } \\
\hline & Min & Max & Avg & Min & Max & Avg & Min & Max & Avg & Min & Max & Avg & Min & Max & Avg & Min & Max & Avg \\
\hline Urology & 30 & 285 & 122.5 & 81 & 283 & 174.75 & 21 & 253 & 91 & 98 & 230 & 164.50 & 28 & 101 & 70 & 1 & 9 & 4.25 \\
\hline Radiology & 4 & 48 & 30.83 & 0 & 252 & 92.83 & 3 & 213 & 69.17 & 78 & 303 & 181 & 0 & 288 & 88.17 & 1 & 43 & 17.33 \\
\hline $\begin{array}{l}\text { Trauma } \\
\text { center }\end{array}$ & 11 & 331 & 119.67 & 17 & 230 & 150 & 28 & 79 & 47.33 & 320 & 665 & 518.33 & 0 & 122 & 49 & 9 & 135 & 73 \\
\hline Pediatrics & 0 & 150 & 36.67 & 0 & 627 & 163 & 1 & 313 & 115.67 & 56 & 259 & 144.67 & 0 & 47 & 14.83 & 1 & 13 & 4.17 \\
\hline $\begin{array}{l}\text { Laboratory } \\
\text { and blood } \\
\text { bank }\end{array}$ & 1 & 165 & 70 & 118 & 220 & 178.17 & 13 & 138 & 51.33 & 161 & 354 & 256.67 & 6 & 15 & 9.17 & 0 & 35 & 6.33 \\
\hline Neurology & 44 & 156 & 81.33 & 93 & 193 & 159.67 & 59 & 135 & 84.33 & 190 & 288 & 223.33 & 7 & 38 & 17.67 & 2 & 4 & 3 \\
\hline Neurosurgery & 14 & 263 & 112.67 & 0 & 218 & 132.67 & 14 & 59 & 36 & 15 & 715 & 286.33 & 27 & 53 & 44 & 4 & 12 & 6.67 \\
\hline Surgery & 9 & 288 & 66.17 & 30 & 690 & 286.50 & 23 & 201 & 68.17 & 231 & 372 & 277.33 & 6 & 129 & 30.33 & 1 & 6 & 3.17 \\
\hline Cardiology & 37 & 72 & 51 & 90 & 196 & 133.33 & 42 & 261 & 188 & 157 & 510 & 285.33 & 4 & 6 & 5.33 & 1 & 3 & 2 \\
\hline Anesthesia & 4 & 360 & 161.25 & 30 & 321 & 168 & 12 & 179 & 79.25 & 225 & 854 & 487.75 & 0 & 72 & 22 & 1 & 152 & 40.25 \\
\hline Others & 5 & 60 & 30.17 & 0 & 251 & 91.17 & 12 & 205 & 74.67 & 156 & 635 & 332.17 & 6 & 10 & 7.17 & 2 & 35 & 13.17 \\
\hline
\end{tabular}

Figures in days

Table 3: Department-wise different components of ELT

\begin{tabular}{|c|c|c|c|c|c|c|c|c|c|}
\hline \multirow[t]{2}{*}{ Department } & \multicolumn{3}{|c|}{$E L T 1$} & \multicolumn{3}{|c|}{ ELT2 } & \multicolumn{3}{|c|}{ ELT3 } \\
\hline & Min. & Max. & Avg. & Min. & Max. & Avg. & Min. & Max. & Avg. \\
\hline Urology & 2 & 148 & 92 & 5 & 279 & 124 & 0 & 71 & 20.25 \\
\hline Radiology & 37 & 690 & 252.17 & 45 & 160 & 91.50 & 26 & 274 & 141.50 \\
\hline Trauma center & 212 & 306 & 247.67 & 125 & 315 & 191.67 & 0 & 22 & 9 \\
\hline Pediatrics & 37 & 114 & 80 & 0 & 135 & 35.67 & 0 & 60 & 12.50 \\
\hline Laboratory and blood bank & 10 & 91 & 33.17 & 7 & 174 & 58.83 & 0 & 331 & 78 \\
\hline Neurology & 54 & 124 & 89.33 & 42 & 81 & 56.67 & 8 & 84 & 45.33 \\
\hline Neurosurgery & 30 & 224 & 128.67 & 0 & 138 & 89 & 0 & 227 & 95.67 \\
\hline Surgery & 27 & 443 & 210.17 & 18 & 248 & 104.50 & 0 & 155 & 37.17 \\
\hline Cardiology & 2 & 99 & 50.33 & 21 & 57 & 36 & 2 & 7 & 5 \\
\hline Anesthesia & 80 & 690 & 264.50 & 258 & 597 & 403.25 & 0 & 15 & 5 \\
\hline Others & 60 & 395 & 181.33 & 18 & 72 & 44.50 & 0 & 22 & 7.33 \\
\hline
\end{tabular}

Figures in days

there was an aberration in anesthesia department where the situation was reverse.

\section{Criticality of Equipment for Analysis of Lead Time of Capital Equipment}

Based upon the classification of all equipment under study as per VED analysis, the observations were analyzed in respect of ILT and ELT. The classification of various equipment was decided in consultation with respective HODs on their perception about the criticality of equipment. After classification, '29 equipments' were vital, '15' as essential and ' 6 ' as desirable category.

On study of ILT and ELT among the above category of equipments, it was observed that the highest 'average ILT' 


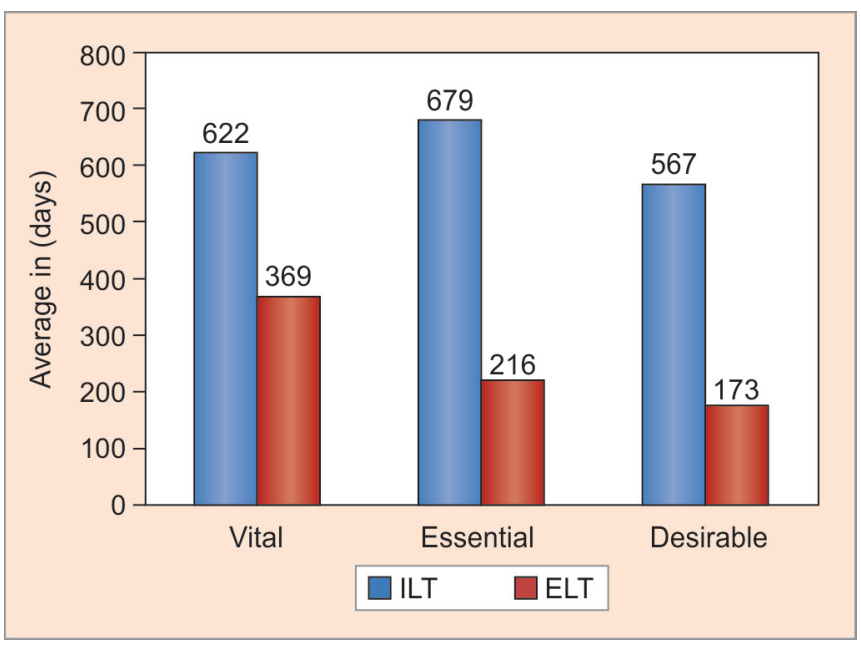

Graph 2: Criticality wise (VED) average lead time analysis

was seen in equipments belonging to 'essential' category and followed by 'vital' category while lowest 'average ILT' was observed in 'desirable' category. Similarly, the highest 'average ELT' was seen in equipments belonging to 'vital' category followed by 'essential' category and lowest 'average ELT' was seen in 'desirable' category (Graph 2).

\section{Internal Lead Time - Criticality Wise}

The subcomponents wise analysis of ILT indicates that the highest value of maximum ILT was for ILT1 and 2: essential category, ILT3: desirable category, ILT4, 5 and 6: vital category. On the contrary, lowest value of minimum ILT subcomponent was observed as follows: ILT1: desirable category, ILT2: vital category, ILT3: essential category, ILT4, 5 and 6: desirable category (Table 4).

Intra departmental observations: It was observed that major components of ILT in almost all the three categories was ILT4 followed by ILT2, i.e. technical bid evaluation followed by framing the specifications. The other components of ILT were not that time consuming.

\section{External Lead Time-Criticality Wise}

The subcomponents wise analysis of ELT is depicted in Table 5. The highest value of maximum ELT subcomponent was observed as follows: ELT1 and 2: vital category, ELT3: essential category. On the other hand, lowest value of minimum ELT subcomponent was observed as follows: ELT1: 'essential' category, ELT 2 and 3: desirable.

It was further observed that ELT1 was the major time component vis-a-vis of total ELT in all three categories followed by ELT2 and ELT3 component.

\section{Purchase Process-wise Analysis of Lead Time of Capital Equipment}

The data were analyzed in respect of different purchase process, i.e. 'open tender', 'open tender with higher authority

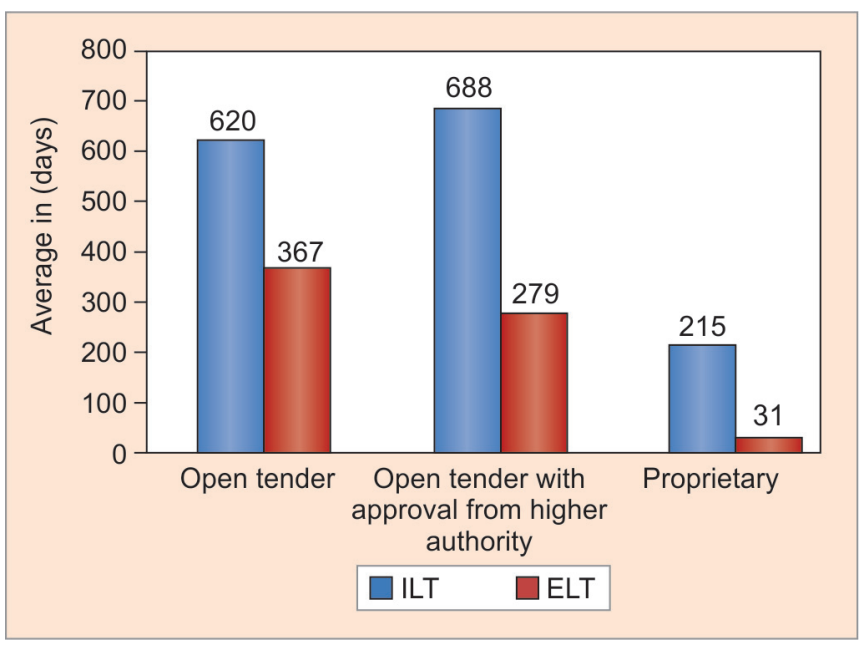

Graph 3: Purchase process-wise average lead time analysis

approval', 'proprietary purchase'. It was observed that the highest 'average ILT' was seen in equipment purchased through 'open tender with higher authority approval' followed by 'open tender' while lowest 'average ILT' was observed in 'proprietary purchase' process. Similarly, the highest 'average ELT' was seen in equipment purchased through 'open tender' followed by 'open tender with higher authority approval' and lowest 'average ELT' was seen in 'proprietary purchase' (Graph 3).

\section{Internal Lead Time_Purchase Process Wise}

The subcomponents wise analysis of ILT as per purchase process of equipment indicates that the highest value of maximum ILT was for ILT1 and 2: 'open tender', ILT3 and 4: 'open tender with higher authority approval', ILT5: 'open tender' and ILT 6: 'open tender with higher authority approval'. On the contrary, lowest value of minimum ILT subcomponent was observed from ILT1 to 6: proprietary purchase' (Table 6).

\section{External Lead Time_-Purchase Process Wise}

The subcomponents wise analysis of ELT indicates that the highest value of maximum ELT from ELT1 to 3 was for open tender', and lowest value of minimum ELT subcomponent was observed from ELT1 to 3 for proprietary purchase' (Table 7).

\section{Internal Lead Time (Total)}

It has been observed, that taking average of all equipment under study, ILT 2 component constitute about $42 \%$ of the total ILT followed by ILT 4 constituting $28 \%$ as shown in Figure 2.

\section{External Lead Time (Total)}

Similarly, the ELT1 constitute about $75 \%$ of the total ELT followed by ELT2 constituting 25\% as shown in Figure 2. 


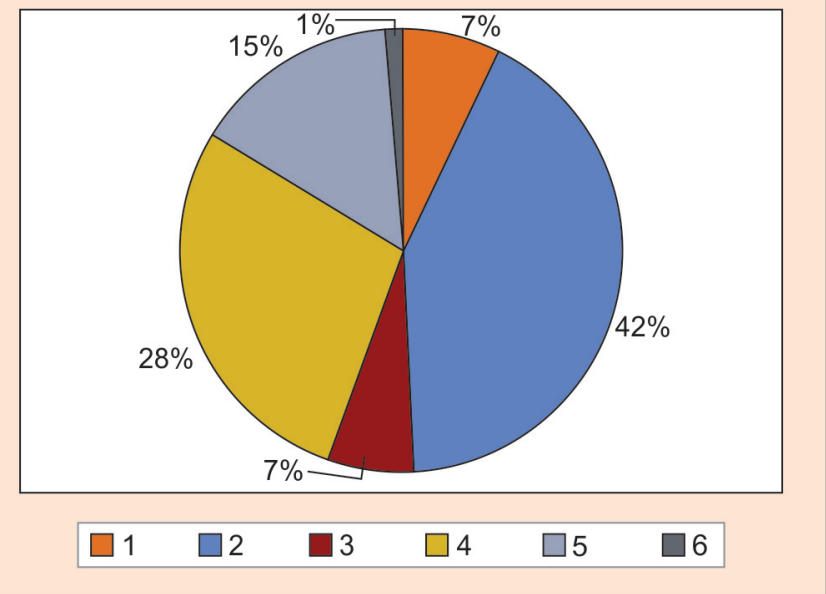

Total internal lead time: It has been observed, taking average of all equipments under study, ILT2 component constitute about $42 \%$ of the total ILT followed by ILT4 constituting $28 \%$ as shown in above graph

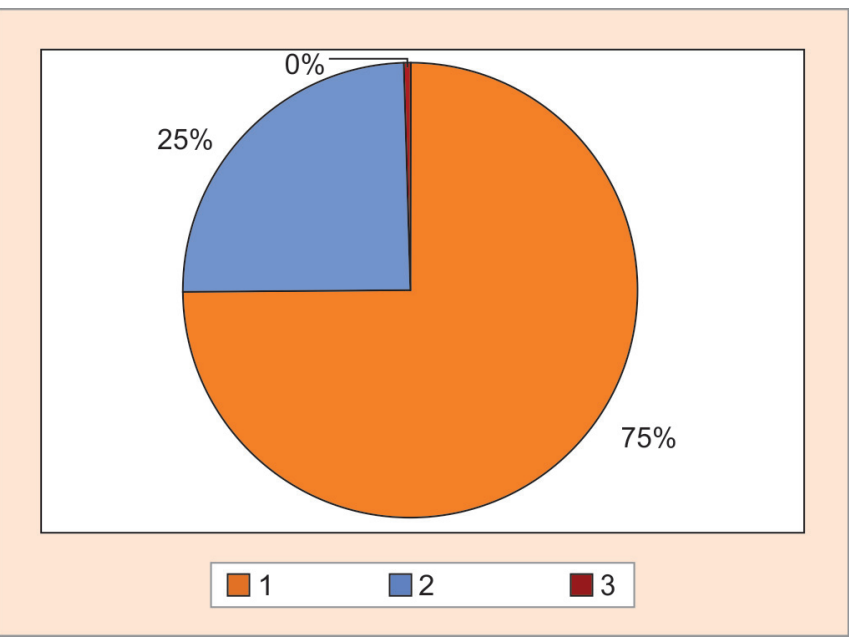

Total external lead time: Similarly, the ELT1 constitute about $75 \%$ of the total ELT followed by ELT2 constituting $25 \%$ as shown in above graph

Fig. 2: Comparison of total internal and external lead time

Table 4: Criticality-wise different components of ILT

\begin{tabular}{|c|c|c|c|c|c|c|c|c|c|c|c|c|c|c|c|c|c|c|}
\hline \multirow{2}{*}{$\begin{array}{l}\text { Type of } \\
\text { category }\end{array}$} & \multicolumn{3}{|c|}{ ILT1 } & \multicolumn{3}{|c|}{ ILT2 } & \multicolumn{3}{|c|}{ ILT3 } & \multicolumn{3}{|c|}{ ILT4 } & \multicolumn{3}{|c|}{ ILT5 } & \multicolumn{3}{|c|}{ ILT6 } \\
\hline & Min. & Max. & Avg. & Min. & Max. & Avg. & Min. & Max. & Avg. & Min. & Max. & Avg. & Min. & Max. & Avg. & Min. & Max. & Avg. \\
\hline Vital & 0 & 360 & 66.17 & 0 & 321 & 115.14 & 3 & 261 & 85.83 & 15 & 854 & 300.14 & 0 & 288 & 37.45 & 1 & 152 & 17.45 \\
\hline Essential & 5 & 288 & 94.80 & 81 & 690 & 226.27 & 21 & 201 & 67 & 98 & 570 & 249.53 & 6 & 129 & 32.20 & 0 & 75 & 9.67 \\
\hline Desirable & 1 & 150 & 48.67 & 0 & 627 & 205.83 & 1 & 313 & 88 & 56 & 295 & 208.83 & 0 & 13 & 7.50 & 0 & 26 & 7.67 \\
\hline
\end{tabular}

Figures in days

Table 5: Criticality-wise different components of ELT

\begin{tabular}{|c|c|c|c|c|c|c|c|c|c|}
\hline \multirow[t]{2}{*}{ Type of category } & \multicolumn{3}{|c|}{ ELT1 } & \multicolumn{3}{|c|}{ ELT2 } & \multicolumn{3}{|c|}{ ELT3 } \\
\hline & Min. & Max. & Avg. & Min. & Max. & Avg. & Min. & Max. & Avg. \\
\hline Vital & 2 & 690 & 182.10 & 0 & 597 & 136.48 & 0 & 274 & 50.17 \\
\hline Essential & 2 & 443 & 103.60 & 5 & 165 & 62.40 & 0 & 331 & 50.40 \\
\hline Desirable & 22 & 395 & 113.33 & 4 & 174 & 57.50 & 0 & 7 & 2.33 \\
\hline
\end{tabular}

Figures in days

Table 6: Purchase process-wise different components of ILT

\begin{tabular}{|c|c|c|c|c|c|c|c|c|c|c|c|c|c|c|c|c|c|c|}
\hline \multirow[t]{2}{*}{ Type of process } & \multicolumn{3}{|c|}{ ILT1 } & \multicolumn{3}{|c|}{ ILT2 } & \multicolumn{3}{|c|}{ ILT3 } & \multicolumn{3}{|c|}{ ILT4 } & \multicolumn{3}{|c|}{ ILT5 } & \multicolumn{3}{|c|}{ ILT6 } \\
\hline & Min. & Max. & Avg. & Min. & Max. & Avg. & Min. & Max. & Avg. & Min. & Max. & Avg. & Min. & Max. & Avg. & Min. & Max. & Avg. \\
\hline Open & 1 & 288 & 74.50 & 0 & 627 & 176.75 & 12 & 261 & 83.55 & 78 & 715 & 248.75 & 6 & 129 & 24.70 & 1 & 75 & 12.15 \\
\hline $\begin{array}{l}\text { Open tender with } \\
\text { approval from } \\
\text { higher authority }\end{array}$ & 0 & 360 & 71.96 & 0 & 690 & 161.19 & 3 & 313 & 85.74 & 173 & 854 & 316.89 & 0 & 288 & 36.3 & 0 & 152 & 16.15 \\
\hline Proprietary & 11 & 128 & 66.67 & 0 & 81 & 27 & 1 & 21 & 12 & 15 & 98 & 56.33 & 12 & 75 & 46.67 & 1 & 13 & 6 \\
\hline
\end{tabular}

Figures in days

Table 7: External lead time (process-wise)

\begin{tabular}{|c|c|c|c|c|c|c|c|c|c|}
\hline \multirow[t]{2}{*}{ Type of process } & \multicolumn{3}{|c|}{ ELT1 } & \multicolumn{3}{|c|}{ ELT2 } & \multicolumn{3}{|c|}{ ELT3 } \\
\hline & Min. & Max. & Avg. & Min. & Max. & Avg. & Min. & Max. & Avg. \\
\hline Open tender & 10 & 690 & 186.70 & 0 & 597 & 116.30 & 0 & 331 & 64 \\
\hline $\begin{array}{l}\text { Open tender with approval from } \\
\text { higher authority }\end{array}$ & 2 & 690 & 137.48 & 7 & 468 & 107.56 & 0 & 274 & 34.41 \\
\hline Proprietary & 11 & 128 & 66.67 & 0 & 81 & 27 & 1 & 21 & 12 \\
\hline
\end{tabular}

Figures in days 


\section{DISCUSSION AND CONCLUSION}

It has been observed that the procurement procedure in the hospital under study is as per the standard guidelines prescribed by Govt of India in General Financial Rules ${ }^{5}$ and guidelines issued by MOHFW and DGHS ${ }^{6}$ in this regard.

In lead time analysis, it was observed that there is a variation in the total lead time, ILT, ELT and their subcomponents for each of capital equipment and in different departments. The longest average total ILT was seen in equipment belonging to anesthesia department and minimum belonging to radiology and pediatrics department, although the procurement process remains the same for all the departments of the hospital.

It was further observed that out of the average total ILT, maximum time was taken by ILT4 followed by ILT2 component. Since activities in both ILT2 and ILT4, i.e. laying down the specification and technical bid evaluation are the responsibility of the individual department. Hence, the overall delay can also be attributed to the individual department. It was further observed that ILT2 and ILT4 component constituted around $70 \%$ of the total ILT for almost all the equipment under study. This gives us the assumption that in order to reduce the ILT significantly and effectively, intervention at the departmental level is needed for strengthening and expediting the procedure. On interview with the concerned HODs, it was felt that inadequate knowledge about the procurement procedure, lack of adequate information on product, lack of clarity among the team members about the specifications to be framed, influence of the bidders on the experts, time constraints with the experts and lack of secretarial support to the committee are some of the important factors contributing to the delay at the departmental level.

In case of ELT, $75 \%$ time was consumed by ELT1, i.e. the delivery time and receipt of equipment. This time can be marginally reduced by imposing strict conditions on the suppliers regarding delivery time. However, it has a limited scope since most of the equipment are imported and have to be shipped from abroad. Further, in many equipment installation and commissioning process took longer time, since there was delay in site preparedness before installation of equipment.

In the process wise lead time analysis, it was concluded that the shortest time was taken by proprietary purchase followed by open tender and maximum time in open tender with approval from higher authority.

In view of the inherent procedure involved in all three types of purchase procedures, these observations are on the expected lines. However, it was also observed here that the ILT2 and ILT4 component of internal lead time had the major time share in all the three types of process. Hence, there is a scope to reduce the total lead time further in all the three categories here also by adopting and expediting the process at the departmental level. In addition, the time can be further reduced, in case policies are reviewed in respect of inadequate bid response and financial powers of competent authorities, since these two are also the bottleneck areas.

On an analysis of lead time in VED category, it has been concluded that no concept of VED analysis is applied in the procurement of equipment. This is evident from the fact that the minimum lead time was seen in desirable followed by maximum in essential or vital equipment. Hence, there is a need to develop the procurement process in line with the VED analysis. During the study and on interview with the user, officials of purchase department VED concept was not found in practice at any level.

In DGHS guidelines, certain time frames have been suggested for various activities of procurement for central government hospital. In our study, the lead time (ILT and ELT) has been found to be much higher than the suggested time lines in most of the equipment under study. In certain isolated cases, the lead time (ILT and ELT) is exceptionally long and inordinate delay in whole process. In such isolated cases, the major reasons for delay was technical bid evaluation and in some cases, retendering, unusual delivery time/installation and commissioning.

Therefore, it is concluded that, on taking the average of all equipment under study, ILT 2 component constitute about $42 \%$ of the total ILT followed by ILT 4 constituting $28 \%$ of the total ILT suggesting that laying down the specification and technical bid evaluation are two major bottlenecks in procurement process of capital equipment at a public sector tertiary care hospital.

\section{RECOMMENDATIONS}

Standardized specifications need to be developed for commonly used equipment and these can be submitted along with submission of demand to purchase department to cut short the delay in ILT2 component.

A standing technical bid evaluation committee should be constituted in each department for technical bid evaluation. The committee should finalise the evaluation in a fixed time bound manner at that place only. The committee members should be trained in regards to purchase procedures and relevant instructions/guidelines issued in this regard by the various authorities.

The practice of categorization of equipment according to VED analysis concept should be introduced in the hospital for effective procurement process.

The delegation of financial powers to the sanctioning authority should be reviewed periodically keeping in view the current cost of equipment and need of technology in 
the hospitals of today. This will avoid unnecessary delay in finalization of purchases where sanction of higher authority is required in the present scenario.

It is much advisable to develop a time bound SOP for the purchase section of the hospital. The SOP should contain detailed steps of procedures, authority and responsibility at each level of hierarchy, rules and regulations regarding tendering process, delegated financial powers, payment procedures, etc.

\section{REFERENCES}

1. Kaur M, Fagerli T. Caroline Temple Bird, Andreas Level, Willi Kawohl. Cited in Department of Health Service ProvisionWHO-(2000), 'How to manage series for healthcare technology, Guide 3.' How to Procure and Commission your Healthcare
Technology'. Available at: http://www.who.int/management/ procure_commission_healthcare.pdf.

2. Technical discussions on 'The role of medical devices and equipment in contemporary health'. EM/RC53/Tech. Disc. 2 2006. Available at: www.siteresources.worldbank.org/ intmnaregtophealth/resources/role_medical_devices_heal. Last visited on Pvt Ltd. 2012-01-24.

3. Gupta S, Kant S. Strategies for hospital equipment planning and selection. In Hospital Store Management: An Integrated Approach. 1st ed. Jaypee Brothers Medical Publishers Pvt. Ltd. 2007;129.

4. National Institute of Health and Family Welfare, PG. Certificate course in Hospital Management Module. Equipment and Material Management 2002;24.

5. Swamy's compilation of 'General Financial Rules 2005'.

6. Government of India. Ministry of Finance. Department of Expenditure. Manual on Policies and Purchase of Goods and Services, 2006 Aug 31. 